\title{
HERITABILITY OF DORSAL SPINES IN THE FOURSPINE STICKLEBACK (APELTES QUADRACUS)
}

\author{
D. W. HAGEN AND D. M. BLOUW \\ Department of Biology, University of New Brunswick, Fredericton, N.B., \\ Canada E3B $6 E 1$
}

Received 11.i.83

\section{SUMMARY}

Heritabilities of dorsal spine number in Apeltes quadracus are estimated for four widely separated sites in New Brunswick, Canada. The additive genetic variance is high with values ranging from $0.47 \pm 0.049$ to $0.80 \pm 0.128$; average heritability for the four sites is $0.61 \pm 0.068$. The sexes do not differ for estimates. Directional selection over three generations shows a rapid response suggesting that few loci are involved and that stabilizing selection acts on natural populations.

\section{INTRODUCTION}

The fourspine stickleback (Apeltes quadracus) is well suited to studies in ecological genetics (Blouw and Hagen, 1981; Blouw, 1982). This small fish is conspicuously polymorphic for the number of dorsal spines (fig. 1). The

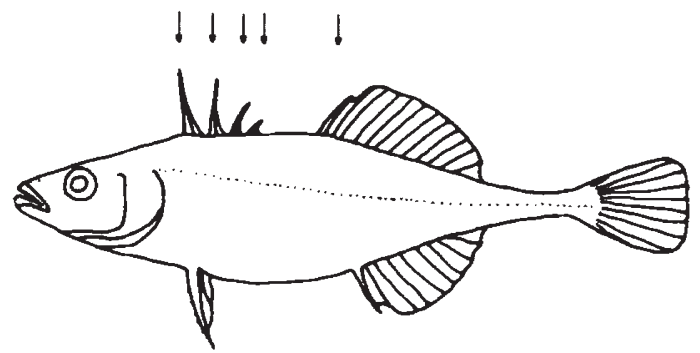

FIG. 1. Arrows indicate the five dorsal spines of Apeltes quadracus. Spine number varies from two to seven.

four and fivespined morphs occur at highest frequencies in almost all localities, and although spine number varies from two to seven these extremes are very rare (Blouw and Hagen, 1981; Blouw, 1982). The adaptive significance of this polymorphism is the subject of our research and like all studies in ecological genetics we require information on its mode of inheritance. The subject of this paper is to give estimates of heritability for dorsal spines from four widely separated populations in New Brunswick, and to report some limited results for directional selection for increased and decreased spine number over three generations.

\section{MATERIALS AND METHODS}

Apeltes is found throughout the Maritime Provinces of Canada and is most common in brackish water along the coast, but occasionally it occurs 
in fresh or salt water. As mentioned, the four and fivespined morphs usually occur at highest frequencies but populations are frequently polymorphic with threes and sixes as well. Details of the distribution, ecology, and polymorphism are given in Blouw and Hagen (1981) and Blouw (1982).

The four estimates of heritability are based on 13 families each from French Fort Cove, Daigle Inlet and Richibucto River, and 22 families from Big Cove for a total of 61 families. Three sites are brackish water and one (French Fort Cove) is fresh water. Stocks for parents were collected with a net from the four sites in June when large numbers of mature adults are available, and were transported to the laboratory in styrofoam containers. Crosses were made within 48 hours after arrival. Eggs of mature females were deposited into a small petri dish $(25 \mathrm{~mm})$ containing a few drops of water by gently pressing her abdomen. The testes of a male were immediately removed from a slit in the coelom, placed in the dish, and chopped with forceps to release sperm over the eggs.

Families were reared as uniformly as possible in separate aquaria (681) containing brackish water $(5 \%)$. Each clutch was placed in a small nylon net above a vigorously bubbling airstone and the tank was cleansed by charcoal filter (Dynaflow magnetic). Photoperiod was held at 14 hours daylight per day using Duro-Test, Vita-Lite tubes (natural daylight spectrum) suspended $2 \mathrm{~m}$ above the aquaria. Temperature was held at $18^{\circ} \mathrm{C} \pm$ 0.5 with a thermostat control system built into the laboratory; this temperature was chosen because it approximates temperatures at nest sites in the field $(n=42)$, and the same rationale applies to the salinity we chose.

When the fry hatched they were counted and released into the tanks. They were fed crushed infusoria tablets for three days, and thereafter were fed nauplii of live brine shrimp twice daily to maturity. With this procedure mortality was nil in all clutches.

We also applied directional selection over three generations for decreased and increased spine number. The laboratory methods were as given above with the following exceptions. When the offspring in each generation were two months old the photoperiod was decreased from 14 hours to 8 hours daylight per day and temperature was decreased to $8^{\circ} \mathrm{C}$ (simulating winter conditions). After seven weeks, daylight and temperature were again set to 14 hours and $18^{\circ} \mathrm{C}$ (simulating summer conditions). This manipulation of temperature and photoperiod is necessary to bring offspring into sexual maturity (Baggerman, 1957).

Counts of dorsal spines were made at sexual maturity which corresponds to an age of about four months in the laboratory. Methods for counting spines follow Blouw and Hagen (1981) and the observational error is negligible ( $<1$ per cent).

\section{ANALYSIS AND Discussion}

Consider the four parental populations; the distributions and means of dorsal spines for the two sexes are shown in table 1 . As is almost always the case (Blouw and Hagen, 1981), here too the sexes are homogeneous for spine number.

The basic data for parents and offspring are given in table 2. We are unable to fit the data to any simple model of Mendelian inheritance with alleles at one or two loci. Thus we assume the trait is polygenically controlled and have used the methods of quantitative genetics (Falconer, 1981). 
TABLE 1

Dorsal spine number for male and female Apeltes from the four parental populations with tests of homogeneity between sexes by chi-square

\begin{tabular}{|c|c|c|c|c|c|c|c|c|}
\hline \multirow[b]{2}{*}{ Source } & \multirow[b]{2}{*}{ Sex } & \multicolumn{4}{|c|}{ Spine number } & \multirow[b]{2}{*}{ Mean } & \multirow[b]{2}{*}{$x^{2}$} & \multirow[b]{2}{*}{$P$} \\
\hline & & 3 & 4 & 5 & 6 & & & \\
\hline \multirow{2}{*}{$\begin{array}{l}\text { French Fort } \\
\text { Cove }\end{array}$} & $\delta$ & & 32 & 85 & & \multirow[t]{2}{*}{4.73} & \multirow[t]{2}{*}{$<0.001$} & \multirow[t]{2}{*}{$>0.9$} \\
\hline & 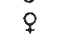 & & 37 & 97 & 1 & & & \\
\hline \multirow{2}{*}{ Daigle Inlet } & $\delta$ & 1 & 358 & 142 & 1 & \multirow[t]{2}{*}{$4 \cdot 28$} & \multirow[t]{2}{*}{$0 \cdot 240$} & \multirow[t]{2}{*}{$0.5<P<0.9$} \\
\hline & $q$ & 2 & 488 & 182 & 1 & & & \\
\hline \multirow{2}{*}{$\begin{array}{l}\text { Richibucto } \\
\text { River }\end{array}$} & 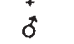 & & 27 & 9 & 1 & \multirow[t]{2}{*}{$4 \cdot 23$} & \multirow[t]{2}{*}{0.609} & \multirow[t]{2}{*}{$0.1<P<0.5$} \\
\hline & q & & 62 & 16 & & & & \\
\hline \multirow[t]{2}{*}{ Big Cove } & $\delta$ & 2 & 678 & 665 & 5 & \multirow[t]{2}{*}{$4 \cdot 52$} & \multirow[t]{2}{*}{$5 \cdot 778$} & \multirow[t]{2}{*}{$0.05<P<0.10$} \\
\hline & $q$ & 5 & 860 & 927 & 18 & & & \\
\hline
\end{tabular}

TABLE 2

Dorsal spine number for parents and offspring from four sites with tests of homogeneity between sexes within families (Fisher's Exact Test) and combined within sites (chi-square)

\begin{tabular}{|c|c|c|c|c|c|c|c|c|c|c|}
\hline \multirow[b]{3}{*}{ Clutch } & \multicolumn{9}{|c|}{ Offspring Phenotypes } & \multirow[b]{3}{*}{$P$} \\
\hline & Parents & \multicolumn{4}{|c|}{ Male } & \multicolumn{4}{|c|}{ Female } & \\
\hline & $q$ & 3 & 4 & 5 & 6 & 3 & 4 & 5 & 6 & \\
\hline
\end{tabular}

\section{French Fort Cove}

$\begin{array}{ccccrrrrrrrr}1 & 4 & 4 & - & 8 & 3 & - & - & 5 & 4 & - & 0.20 \\ 2 & 4 & 4 & - & 5 & 2 & - & - & 6 & 2 & - & 0.68 \\ 3 & 4 & 5 & - & 7 & 4 & - & - & 10 & 3 & - & 0.79 \\ 4 & 4 & 5 & - & 4 & 8 & - & - & 3 & 4 & - & 0.95 \\ 5 & 5 & 4 & - & 4 & 6 & - & - & 5 & 4 & - & 0.83 \\ 6 & 5 & 4 & - & 5 & 6 & - & - & 5 & 5 & - & 0.82 \\ 7 & 5 & 5 & - & - & 12 & - & - & 2 & 11 & - & 0.52 \\ 8 & 5 & 5 & - & 10 & 7 & - & - & 8 & 4 & - & 0.97 \\ 9 & 5 & 5 & - & 3 & 8 & - & - & 2 & 11 & 1 & - \\ 10 & 5 & 5 & - & 1 & 12 & - & - & 1 & 11 & - & 0.52 \\ 11 & 6 & 6 & - & - & 9 & 5 & - & - & 5 & 6 & 0.18 \\ 12 & 6 & 6 & - & - & 4 & 5 & - & - & 5 & 4 & \overline{0} \\ 13 & 6 & 6 & - & - & 5 & 7 & - & - & 8 & 6 & 0.70 \\ \text { Pooled } & - & - & - & 47 & 86 & 17 & - & 47 & 77 & 17 & \left(\chi^{2}(2)=0.22 ;\right. \\ & & & & & & & & & & & 0.5<F<0.9)\end{array}$

$\begin{array}{ccccrrrrrrrc}1 & 3 & 3 & 4 & 8 & - & - & 7 & 4 & - & - & 0.30 \\ 2 & 3 & 3 & 4 & 7 & - & - & 3 & 5 & - & - & 0.67 \\ 3 & 3 & 3 & 5 & 3 & - & - & 3 & 6 & - & - & 0 \cdot 09 \\ 4 & 4 & 4 & 2 & 10 & - & - & 3 & 8 & - & - & 0.91 \\ 5 & 4 & 4 & - & 9 & - & - & - & 8 & - & - & - \\ 6 & 4 & 4 & - & 6 & - & - & - & 7 & - & - & - \\ 7 & 5 & 5 & - & 2 & 5 & 3 & - & 2 & 7 & 2 & - \\ 8 & 5 & 5 & - & 4 & 11 & - & - & 3 & 13 & - & 0.34 \\ 9 & 5 & 5 & - & 4 & 8 & - & - & 5 & 7 & - & - \\ 10 & 6 & 6 & - & - & 7 & 2 & - & - & 6 & 2 & 0.48 \\ 11 & 6 & 6 & - & - & 8 & 2 & - & - & 12 & 3 & 0.63 \\ 12 & 6 & 6 & - & - & 6 & 3 & - & - & 7 & 3 & 0.74 \\ 13 & 6 & 6 & - & - & 11 & 3 & - & - & 7 & 4 & 0.20 \\ \text { Pooled } & - & - & 15 & 53 & 56 & 13 & 16 & 48 & 59 & 14 & \left(\chi_{(3)}^{2}=0.40\right. \\ & & & & & & & & & & & 0.5<P<0.9)\end{array}$


TABLE 2 (Cont.)

\begin{tabular}{|c|c|c|c|c|c|c|c|c|c|c|c|}
\hline \multicolumn{12}{|c|}{ Richibucto Estuary } \\
\hline 1 & 4 & 4 & 1 & 6 & - & - & 1 & 11 & - & - & 0.25 \\
\hline 2 & 4 & 4 & - & 3 & - & - & - & 6 & - & - & - \\
\hline 3 & 4 & 4 & - & 8 & - & - & - & 7 & - & - & - \\
\hline 4 & 4 & 4 & 2 & 8 & - & - & 1 & 7 & - & - & 0.29 \\
\hline 5 & 5 & 4 & - & 6 & 8 & - & - & 3 & 3 & - & 0.85 \\
\hline 6 & 5 & 4 & - & 12 & 1 & - & - & 9 & 2 & - & $0 \cdot 16$ \\
\hline 7 & 5 & 4 & - & 9 & 1 & - & - & 6 & - & - & 0.75 \\
\hline 8 & 4 & 5 & - & 13 & 2 & - & - & 12 & - & - & 0.60 \\
\hline 9 & 4 & 5 & - & 6 & - & - & - & 9 & - & - & - \\
\hline 10 & 4 & 5 & - & 5 & 5 & - & - & 3 & 3 & - & 0.61 \\
\hline 11 & 5 & 5 & - & 2 & 6 & 2 & - & 1 & 7 & 3 & - \\
\hline 12 & 5 & 5 & - & 1 & 7 & 2 & - & 3 & 5 & 3 & - \\
\hline 13 & 6 & 6 & 一 & - & 6 & 3 & - & - & 6 & 2 & 0.87 \\
\hline Pooled & - & - & - & 79 & 36 & 7 & 2 & 77 & 26 & 8 & $\begin{array}{c}\left(\chi^{2}(2)=1.13\right. \\
0.5<P<0.9)\end{array}$ \\
\hline
\end{tabular}

Big Cove

\begin{tabular}{rrrlrrrrrrrr}
1 & 3 & 3 & - & 13 & - & - & - & 7 & - & - & - \\
2 & 3 & 3 & - & 6 & - & - & - & 6 & - & - & - \\
3 & 3 & 3 & - & 6 & - & - & 1 & 7 & - & - & $0 \cdot 86$ \\
4 & 3 & 4 & - & 3 & 6 & - & - & 3 & 2 & - & 0.69 \\
5 & 3 & 4 & - & 10 & 2 & - & - & 4 & 6 & - & $0 \cdot 009$ \\
6 & 3 & 4 & - & 5 & 10 & - & - & 4 & 8 & - & 0.69 \\
7 & 4 & 4 & - & 3 & 13 & - & - & 4 & 12 & - & - \\
8 & 4 & 4 & - & 2 & 10 & - & - & 4 & 7 & - & 0.55 \\
9 & 4 & 4 & - & 6 & 11 & - & - & 5 & 13 & - & $0 \cdot 40$ \\
10 & 5 & 5 & - & - & 9 & - & - & - & 6 & - & - \\
11 & 5 & 5 & - & 1 & 13 & - & - & 2 & 15 & - & $0 \cdot 85$ \\
12 & 5 & 5 & - & 3 & 9 & - & - & 1 & 12 & - & 0.08 \\
13 & 6 & 5 & - & - & 12 & - & - & - & 5 & - & - \\
14 & 6 & 5 & - & - & 10 & - & - & - & 14 & - & - \\
15 & 6 & 5 & - & - & 8 & 4 & - & - & 8 & 5 & 0.50 \\
16 & 5 & 6 & - & - & 5 & 5 & - & - & 7 & 6 & 0.81 \\
17 & 6 & 6 & - & - & 4 & 2 & - & - & 2 & 6 & 0.03 \\
18 & 6 & 6 & - & - & 2 & 8 & - & - & 3 & 7 & - \\
19 & 6 & 6 & - & - & 2 & 9 & - & - & 1 & 10 & 0.21 \\
20 & 6 & 2 & - & 3 & 4 & 4 & - & 2 & 10 & 1 & - \\
21 & 6 & 3 & - & 6 & 4 & - & - & 5 & 7 & - & $0 \cdot 20$ \\
22 & 6 & 3 & - & 7 & 5 & - & - & 2 & 5 & - & 0.08 \\
Pooled & - & - & - & 74 & 139 & 32 & 1 & 56 & 143 & 35 & $\left(\chi^{2}(2)=2 \cdot 19 ;\right.$ \\
& & & & & & & & & & & $0 \cdot 1<P<0 \cdot 5)$ \\
\hline
\end{tabular}

We are dealing with a meristic trait where parents and offspring may have either three, four, five or six spines. To our knowledge threshold models (Falconer, 1981) have not been used to estimate heritability for polychotomous traits. Thus we have employed the regression of offspring on mid-parent to estimate heritability in the "narrow" sense (additive genetic variance). Several points should be raised before discussing the heritabilities. First, the regression of offspring on mid-parent is valid only if the variances are equal between sexes, which they are for both the parental populations (table 1) and the laboratory reared offspring (table 2). Only two of 61 families are heterogenous and this can arise by chance alone; the overall distributions of spines between sexes within sites are also homogeneous. Second, we deliberately crossed parents with extremes 
of high and low spine counts by searching through large stocks from each site, and in fact most of the matings are positive assortative (table 2). This will not affect the heritability estimate and has the advantage of decreasing the sampling error of the regression (Falconer, 1981). Third, the problem of unequal family size arises. Methods of weighting families are discussed by Reeve (1955) and all have certain difficulties; with our data the average clutch size is 21 and there is little variation (table 2) so we give equal weight to all families.

Heritability in the "narrow" sense is defined as the ratio of the additive genetic variance to the total phenotypic variance. For regression of offspring on mid-parent the heritability $\left(h^{2}\right)$ is estimated from the regression coefficient ( $b$ in table 3 ). Regression coefficients for male and female offspring on mid-parent for the four populations do not differ significantly (both regression coefficients fall within the two confidence limits; table 3).

TABLE 3

Regression coefficients (b), standard errors $\left(S . E_{b_{b}}\right.$ ) and upper and lower $95 \%$ confidence limits for male and female offspring on mid-parent

\begin{tabular}{lcccccc}
\hline Source & Sex & $N$ & $b$ & S.E. $b$ & UCL & LCL \\
\hline French Fort Cove & $\delta$ & 13 & 0.586 & 0.064 & 0.727 & 0.445 \\
& $o$ & 13 & 0.589 & 0.068 & 0.736 & 0.436 \\
Daigle Inlet & $\delta$ & 13 & 0.590 & 0.042 & 0.682 & 0.498 \\
& $\$$ & 13 & 0.606 & 0.043 & 0.701 & 0.511 \\
Richibucto River & $\delta$ & 13 & 0.817 & 0.124 & 1.090 & 0.544 \\
Big Cove & $\wp$ & 13 & 0.777 & 0.137 & 1.079 & 0.475 \\
& $\delta$ & 22 & 0.449 & 0.058 & 0.570 & 0.328 \\
& $\wp$ & 22 & 0.488 & 0.046 & 0.584 & 0.392 \\
\hline
\end{tabular}

Since sexes do not differ they are combined to obtain heritabilities for each of the four populations (table 4). Heritabilities for dorsal spines vary from a low of $h^{2}=0.47 \pm 0.049$ at Big Cove to a high of $h^{2}=0.8 \pm 0.128$ at Richibucto River. All slopes differ significantly from zero.

Following Rutledge et al., (1973) we can obtain an average heritability and standard error from the estimates for the four populations (table 4). This gives $h^{2}=0.61 \pm 0.068$. That is, if we randomly sample populations in this geographic region, we expect the average heritability for dorsal spines to be 61 per cent, and 95 per cent of the populations should fall in the range of heritabilities from 40 per cent to 83 per cent.

We would like to know if there are maternal effects for dorsal spines, and in principle could evaluate this by regressing offspring on the male

TABLE 4

Regression coefficients (b) for offspring on mid-parent and their standard error (S.E.b), with t-tests of the null hypothesis that $b=0$

\begin{tabular}{llccrc}
\hline \multicolumn{1}{c}{ Source } & $N$ & $b$ & S.E. & \multicolumn{1}{c}{$t$} & $P$ \\
\hline French Fort Cove & 13 & 0.586 & 0.059 & 9.87 & $<0.001$ \\
Daigle Inlet & 13 & 0.595 & 0.039 & 15.32 & $<0.001$ \\
Richibucto River & 13 & 0.798 & 0.128 & 6.23 & $<0.001$ \\
Big Cove & 22 & 0.471 & 0.049 & 9.51 & $<0.001$ \\
\hline
\end{tabular}


and on the female parent and testing for differences in slopes. This is not possible with our data because almost all the parents within crosses have the same phenotypic values (positive assortative matings; see table 2).

We also applied directional selection over three generations for decreased and increased spine number. The original parents come from Big Cove (table 1). We applied selection for decreased and increased spine number to two lines (families). In the second generation crosses were made between rather than within families to minimize the effects of inbreeding. Results for the two lines are combined as they are similar. With only three generations we obtained a remarkable response to selection (table 5); mean

TABLE 5

Directional selection for increased and decreased spine number. The parental population is from Big Cove (table 1). $\bar{x}=$ mean spine number; $N=$ sample size (the two lines selected for increased and decreased spine number are combined)

\begin{tabular}{|c|c|c|c|c|c|c|c|}
\hline \multirow[b]{2}{*}{ Generation } & \multirow[b]{2}{*}{ Parents } & \multicolumn{4}{|c|}{ Spine Number } & \multirow[b]{2}{*}{$\overline{\boldsymbol{x}}$} & \multirow[b]{2}{*}{$N$} \\
\hline & & 4 & 5 & 6 & 7 & & \\
\hline \multicolumn{8}{|l|}{ Decreased } \\
\hline $\mathrm{F}_{1}$ & $50 \times 59$ & 7 & 49 & - & - & $4 \cdot 88$ & 56 \\
\hline$F_{2}$ & $46^{\circ} \times 49$ & 26 & 19 & - & - & 4.43 & 45 \\
\hline $\mathrm{F}_{3}$ & $40^{\circ} \times 49$ & 34 & 12 & - & - & $4 \cdot 26$ & 46 \\
\hline \multicolumn{8}{|l|}{ Increased } \\
\hline $\mathrm{F}_{1}$ & $60^{\circ} \times 69$ & - & 8 & 34 & - & 5.81 & 42 \\
\hline$F_{2}$ & $60^{7} \times 69$ & - & - & 49 & 12 & $6 \cdot 19$ & 61 \\
\hline$F_{3}$ & $78 \times 79$ & - & 一 & 26 & 19 & $6 \cdot 42$ & 45 \\
\hline
\end{tabular}

spine number decreased from an original value of 4.52 (Big Cove, table 1) to 4.26 and increased to 6.42 . As is usual (Falconer, 1981) we have an asymmetrical response with selection for increased spine number being more successful than that for decreased spines. In the lines selected for increased spine number 42 per cent of the offspring had seven spines whereas in natural populations this morph is nonexistent at most localities and never exceeds a frequency of $2 \cdot 1$ per cent. With only three generations and small samples, estimates of heritability from the directional selection are not worthwhile, but with the rapid response to selection two important implications follow:

(a) dorsal spine number is largely controlled by high frequency alleles at relatively few loci (Wright, 1969).

(b) almost all natural populations are polymorphic with high frequencies of four and fivespined morphs, yet we have selected for lines with means of 4.26 and 6.43 and high frequencies of sevens over only three generations. This implies that stabilizing selection acts on dorsal spine variation in natural populations.

The estimates of heritability for four widely separated populations are very high; clearly there is a large store of additive genetic variance available for selection in natural populations, and this is independently verified by our limited data for directional selection.

Krueger (1961) found a negative correlation between frequency of the fivespined morph and environmental salinity, and he suggested that spine 
number may be solely a result of the salinity to which the offspring are exposed. However, the correlation was based on few, small samples and indeed the correlation does not hold in general (Blouw, 1982). The relevant point here is that spine number has a very high heritable component, and although salinity may influence spine number there is no evidence for this.

Acknowledgements. We thank Dr Michael Rose for his helpful suggestions. This work was supported by an NSERC grant A9547 to D. W. Hagen.

\section{REFERENCES}

BAGGERMAN, B. 1957. An experimental study on the timing of breeding and migration in the threespin stickleback, Gasterosteus aculeatus L. Arch. neerl. Zool., 12, 105-318.

BLouw, D. M. 1982. The Adaptive Significance of a Polymorphism for Dorsal Spine Number in Apeltes quadracus and Comparison With Several Coexisting Sticklebacks. Ph.D. Thesis, University of New Brunswick.

BLOUW, D. M. AND HAGEN, D. W. 1981. Ecology of the fourspine stickleback, Apeltes quadracus, with respect to a polymorphism for dorsal spine number. Can. J. Zool., 59, 1677-1692.

FALCONER, D. S. 1981. Introduction to Quantitative Genetics. Longman, New York.

KRUEGER, W. H. 1961. Meristic variation in the fourspine stickleback, Apeltes quadracus. Copeia, 4, 442-450.

REEVE, E. C. R. 1955. The variance of the genetic correlation coefficient. Biometrics, 11, 357-374.

RUTLEDGE, J. J., EISEN, E. J. AND LEGATES, J. E. 1973. An experimental evaluation of genetic correlation. Genetics $75,709-726$.

WRIGHT, S. 1969. The theoretical course of directional selection. Amer. Nat., 103, 561-574. 